\title{
Temporal Reference Frameworks and Nurses' Work Organization
}

\author{
Susan Waterworth
}

\begin{abstract}
Drawing on a qualitative study exploring registered nurses' time management in health care institutions in the United Kingdom, this article reports the findings of the research, as far as they relate to the notion of temporal reference frameworks. The research suggests that temporal reference frameworks function to form background expectancies, which are of major influence in the way in which registered nurses manage their time. Temporal reference frameworks are usually implicit, socially constructed and give meaning to nurses' experiences of time. As such, they act to underpin practical knowledge and to function as time controls. Existing at different levels - individual, team and organizational - the article provides a focus as to how the temporal reference frameworks can match and relate with each other, or clash and as such be a source of conflict and tension. KEY WORDS • health care $\bullet$ nursing $\bullet$ temporal reference frameworks $\bullet$ time management $\bullet$ work organization
\end{abstract}

\section{Introduction}

A reductionist perspective has overshadowed the literature on nurses' time, with a preponderance of studies concerned with time utilization (Waterworth et al., 1999). This is largely representative of the dominance of linear models in attempting to understand time in nursing (Jones, 2001). Few studies in nursing have moved beyond the reductionist perspective to understand the complexity of time in nursing. Those that have present challenges, such as Jones (2001), in applying theory derivation to Adam's (1995) work and exploring temporality, timing and tempo in nursing practice. Other research (Gibson, 1994; Walsh, 1997), while not directly examining time, found that in the course of the

Time \& Society copyright (C) 2003 SAGE (London, Thousand Oaks, CA and New Delhi)

VOL. 12 No. 1 (2003), pp. 41-54

0961-463X[200303]12:1;41-54; 032362

www.sagepublications.com 
research time emerged as an important theme. The small qualitative study by Walsh (1997) of psychiatric nurses and their encounters with patients provides some understanding of the experience of time for nurses. In this latter study, the experience of time as non-linear related to the encounters of nurses with patients. Although the nurse-patient encounters had ended, they remained in the present and continued to influence the nurses as integral to their ongoing experiences. That different perceptions of time exist between patients and health care workers was also found in Gibson's (1994) study, which evaluated a community psychiatric nursing service. In this article, the discussion of temporal reference frameworks on nursing centres assesses the individual, team and organizational dimensions and how they coexist. The focus of the analysis is on the different temporal reference frameworks and how they can relate and match with each other, or clash and be a source of tension and conflict.

\section{Temporal Reference Frameworks}

The conception of temporal reference frameworks applied to health care organizations was introduced by Zerubavel (1979) in his study of the socio-temporal order. Locating his analysis within a hospital as an organization, Zerubavel's (1979) interests concerned temporal patterns illustrative of order and regularity. This perspective, while valuable, also limited the analysis as it ignores the disorder and irregularity that can be found, not only in the world of nursing but in the world in general. Both Melia (1987) and Allen (1997) have referred to the organizational turbulence that can be found in hospital wards. The power dimensions of time were also ignored (Adam 1995), yet time and power are connected and the temporal reference frameworks identified in this research show some evidence of this.

Zerubavel (1979) stated that individuals' temporal patterns are inseparable from a larger whole and as such are organized within some social context. Time management is itself a social construction that underwrites a worker's perception that this is a central aspect of work performance - by suggesting that time itself can be managed. Conventionally time management is postulated as an individual activity and as such the influence of the 'other' and that of the social remains hidden. That it is not an individual activity has largely been unchallenged. In effect a registered nurse's time management is not an individual activity, but as in Adam's (1995) view is subject to a multiple of times and in this discussion, temporal reference frameworks provide for some understanding of the complex and plural temporalition. Temporal reference frameworks provide the background expectations, which comprise a definition of the situation in relation to the nurse performing the act of time management. They act as frames and as such concerning time, the guided doings (Goffman, 1974) of the 
temporal organization of work. Adam (1995) notes how time discipline forms a mostly unquestioned dimension of adult existence. From childhood onwards we are socialized into a western temporal framework with the emphasis on time being used efficiently and budgeted with care (Adam, 1995).

Temporal reference frameworks provide for a sense of cognitive order, as well as the socio-temporal order (Zerubavel, 1979). Within nursing temporal reference frameworks are largely implicit, occur at different levels and directly affect a nurse's temporal organization of work. This temporal organization of work is what Fine (1996) refers to as the constitutive building blocks of duration, tempo, synchronization and sequence. As applied to nursing then how much time (duration) a nurse should spend with a patient, the speed (tempo) at which the nurse carries out her work and the timing (synchronization) of the nurse's work with other nurses or other members of the health care team form the temporal reference frameworks that underwrite the time strategies and repertoire of actions that the registered nurse adopts. A temporal reference framework, as identified in this research, consists of expectations and consequences. This determines the knowing of 'what is relevant' and consists of socially derived knowledge (Schutz, 1964) or mutual knowledge (Giddens, 1987) that largely goes unchallenged as problematic.

\section{Methods and Data Analysis}

This article presents the findings of research as far as they relate to the notion of temporal reference frameworks of registered nurses working in health care institutions in the United Kingdom. This is part of a larger qualitative study on nurses' time management. Data were collected using narratives, focus groups and semi-structured interviews. The sample of participants came from five different health care organizations in the United Kingdom. A range of registered nurses provided a diverse sample in relation to speciality, role and health care organization (Table 1). Observation and informal conversations were also incorporated with the researcher in the role of practitioner researcher (Reed and Procter, 1995). Names of nurses agreeing to participate in the study were elicited from the senior nurse managers of the health care organizations. Participants were contacted by telephone and invited to participate in the study. Narratives, focus groups and semi-structured interviews were tape-recorded to ensure accuracy. The participants were assured of confidentiality and anonymity. Notes from informal conversations and observation were recorded in fieldnote diaries. Data were managed using the qualitative data analysis software package Atlas ti. (Scientific Software Developments). 
TABLE 1

Number of study participants according to data collection method and nursing role

\begin{tabular}{lccc}
\hline & Focus groups & $\begin{array}{c}\text { Semi-structured } \\
\text { interviews }\end{array}$ & $\begin{array}{c}\text { Narrative } \\
\text { accounts }\end{array}$ \\
\hline Clinical manager & 1 & 0 & 0 \\
Sister/Charge nurses & 9 & 6 & 4 \\
Staff nurses & 11 & 9 & 15 \\
Enrolled nurses & 1 & 1 & 0 \\
Specialist nurses & 2 & 6 & 3 \\
Total & 24 & 22 & 22 \\
\hline
\end{tabular}

\section{Findings}

A number of temporal reference frameworks have been identified within the data which illustrate the complexity of time management for registered nurses and the significance of the other when it comes to time. In the hospital environment, most nurses are ward based, although there are increasing numbers of specialist and consultant nurses who, like doctors, may move around the wards and outpatient clinics in an advisory capacity. Effective health care is reliant on a range of health care disciplines, each with its own time slot for working and being there, although nurses have often argued that they provide the nursing constant (Department of Health, 1993), being available when other health care workers are not.

It was found that team temporal reference frameworks exist that influence individual nurses' temporal frameworks and consequently the temporal organization of the nurses' work, as in the following excerpt.

We still have this, if you are on an early shift, by lunchtime you should have all the washes done, the 10 o'clock observations, all those things, most of the work. People who need reviewing and stuff like that. We seem to get that done in the morning, it is in the diary and we put it in the doctor's book and get the doctor down in the morning. But you see in the morning you really wear yourself out and this idea of 24-hour nursing just goes out the window completely. (SS8)

The temporal reference framework influencing this registered nurse's temporal organization of work is about getting most of the work done within her working shift. Clarke (1978) introduced the notion of nurses 'getting through the work' as a definition of nursing as heavy work. Other research has made reference to this on long-stay wards (Evers, 1981) and student nurses in training (Melia, 1987). Expanding on this meaning of getting through the work, Gilligan et al. (1988) argue that getting through the workload may refer to an ethic of respon- 
sibility more associated with women. McNeese-Smith (2001) in her study of nurses' productivity found that the nurses she interviewed associated 'finishing everything' with feelings of being productive. The research presented in this article would offer a different perspective, suggesting that the responsibility is also associated with teamwork and a concern for maintenance of the frame (Goffman, 1974) and this particular temporal reference framework. As such the individual nurse's temporal reference framework is consistent with that of the team's temporal reference framework.

The nurse, by completing certain activities in the morning, is also illustrating her use of what Roth (1963) refers to as signposts. These serve as reference points for progress in a given direction. Roth (1963) notes how they are learned by members of the group through observation of the experience of other members and through the communication of experiences, ideals, myths and hopes among the group members. Reference in this account to 24-hour nursing not being achievable is indicative of the resistance to changing frameworks (Goffman, 1974).

The timetable norm of a group (Roth, 1963) also provides for a standard against which group members' progress can be evaluated. For registered nurses the goal of being able to manage their time brings with it a sense of time control. Tensions can arise between the goal of managing time and the goal of providing quality care to patients. In that the two are often not grouped as mutually compatible, it is suggested that there can be competing frameworks. Getting through the work in their time slot incorporates an expectation that this is a good performance. Slippage is allowed in this performance if something that is regarded as untoward occurs, as a ward sister explains: 'You can have a carotid blowout, half a dozen emergency admissions' (SS5).

It is inappropriate for nurses to hand over work that they should have completed within their shift, but the context influences the degrees of this. For instance, a nurse on an acute admission ward illustrates, 'You do not need to feel guilty if you have not completed everything on your shift because things change so quickly' (II:3). The nurses' time performance is not discredited and the feeling (Hochschild, 1979) of guilt is assuaged. Slippage in performance is accepted in nurses who are new to a place of work and this includes nurses who are students learning their professional role. Nonetheless, these expectations come with attachments and a responsibility to meet the expected performance. As such, if they are not met they can come to be associated with negative views of the nurse as co-worker. Consequently, the performance standards of nurses then come with temporal attachments; for nurses not to get through the work in their time slot alters the temporal organization of work for the oncoming member of the team or the team as a whole. As I have stated previously the temporal reference framework incorporates expectations and consequences. As a ward sister explains, 'I have told the nurses to make sure everything is done, otherwise it is then busy for 
the next shift' (II:4). There is not only a judgement made of an individual nurse as a co-worker but this can reflect on the team as a whole. Zerubavel (1981) relates the temporal synchronicity of the team to Durkheim's 'mechanical solidarity' and as such essential to group working. Disruption to the team's synchronicity puts at risk the presentation of an acceptable face of team time management and has consequences for the next nursing shift's efforts and strategies for time control. For instance, 'catch-up' is a strategy that nurses use when for some reason they feel 'behind time'. Catch-up affects the temporal organization of work in a number of ways and is associated with the feeling of rushing and the rush, which involves nurses attempting to work quicker. Nurses can increase the speed at which they work; the increased speed of working is often described by nurses in the study as 'running' or 'rushing'. As Novek et al. (1990) found, workers can put pressure on each other to keep up the speed of work.

\section{Durational Expectancies}

That nurses require time with patients and vice versa is a given of nursing practice. The uniqueness of nurses as a professional group is temporally defined, since they are the only professionals who are in contact with patients 24 hours a day (Henderson, 1980). A major question that has underpinned numerous workload studies in nursing has been how much time nurses need to 'spend' with patients or more commonly how much time is needed for the completion of certain activities or tasks. This represents a managerial discourse with nurses seen as a resource, their time budgeted and allocated in the completion of these tasks. In the research reported in this article temporal reference frameworks were identified that expose 'durational expectancies' (Zerubavel, 1981), duration itself being a critical building block of the temporal organization of work (Fine, 1996). As a nurse illustrates, 'Because I think that every patient deserves some of your time, just that people need different lengths of it' (SS2).

That patients 'deserve time' is not a belief confined to the profession of nursing. Government health policy (Department of Health, 1997) mirrors this in the allocation of funding to specific groups so that patients not only have time in receiving health care, but also have time incorporated in set standards. For instance, patients admitted to the accident and emergency department have to be assessed within 15 minutes (Sbaih, 2002). In the United States, income to hospitals based on diagnostic related groups means that the length of stay of the patient, if extended beyond the time frame of that particular diagnostic group, can affect payment and decrease hospital income (Padgett, 1998). For the nurses in this study there are two temporal reference frameworks concerned with durational expectancies. The first is 'needing time' which consists of two subtypes, patients needing time and nurses needing time with the patients. The 
second is the temporal reference framework of wasting time. Although some of these temporal reference frameworks can relate to each other, there can also be a clash between the frameworks adding to the time tension or what Peters (1999) refers to as the 'time crunch'.

\section{Needing Time}

The temporal reference frameworks located within the team can determine the durational expectancies as indicated by the patient needing time as follows:

You would feel under pressure if you had not washed and dressed 4 patients or 5 patients by $10 \mathrm{am}$, that you had not done your job properly. It does not happen here, you can spend an hour with 1 patient and that is acceptable, if that is the time that the patient needs. (FG4:21)

In this rehabilitation unit, the nurses viewed being with patients as essential to a successful rehabilitation process and made comparisons with other wards they had worked on, where they experienced not having time to provide care. This 'time debt' (Hochschild, 1997) where nurses experience not having enough time is 'time dissonance': the feeling of needing more time than what is available. Time dissonance in nursing appears to be accepted and taken for granted. The types of patients the nurses care for may have changed, but along with this is how the nurses also acknowledge differences in how they now view their need to have time with patients. Zerubavel (1979) argues that the meaning of a social situation depends to a considerable extent on the temporal context. In relation to doctors' consultation times, Howie (1998) provides a supporting view, arguing that the shorter booking intervals between doctors' appointments (temporal context) serves to encourage behaviours that identify simple problems in contrast to complex problems (social context).

However, there are different levels of meaning or, by reference to Goffman (1974), different frames. The frame can change, and with it the temporal reference framework. In a palliative care unit where patients were admitted with a terminal illness, the temporal reference framework of needing time encompassed the provision of psychological care. The nurses viewed this at least as equally as important and, in some situations, more important than physical care. This also illustrates the group priorities that the nurses will use in their overall performance of time management.

Within the temporal reference framework of needing time, the nurses needed time in order to achieve privileged knowing of the patient illustrated by:

You see the Doctors do not spend time with the patients to know what they want. It is up to us really that it is left on us because we know because we spend time with them and we know their needs a lot more. (FG3.15) 
Nurses believed that they knew the patients better than other health care workers did and they distinguished themselves by their knowledge of the patients, brought about by the time they spent with them. However, the nurses need for 'knowing time' can clash with organizational temporal frameworks.

The organizational temporal reference frameworks are established as yardsticks for processing patients, some of which come as government policy directives, for instance, The Patient's Charter (Department of Health, 1991) standards. The processing of the patient is a reflection of efficiency measures that have brought the development of systems such as critical care pathways, consisting of patient management along a time frame. Although some of the developers of these systems have a financial interest in their success (Blumenthal and Epstein, 1996), in the United Kingdom, approaches to decreasing the length of the hospital inpatient episode have come about as a response to efficiency measures. Of these, reducing the time required for inpatient preoperative preparation has been a strategy widely adopted for surgical patients. For example, preoperative patients may now attend outpatient clinics to be prepared for surgery instead of having a longer stay in hospital before surgery, where traditionally the preoperative preparation was completed. This has required adjustment for some nurses.

It has actually been made more difficult because of changes in the hospital recently. In so much as we are actually getting patients in only the day before surgery. So you have not got too much time to get to know them because they have their anaesthetic and then they are recovering. It has made it more difficult because you tend to if a patient is a bit disorientated you actually find yourself saying, gosh, I wonder whether that lady was maybe withdrawn before surgery. But you actually did not meet that patient until post-operatively you have not had time to assess them. (SS:14)

Fine (1996) contends that in structuring workers' time, organizations create and channel temporal dramas and with this, workers will react emotionally. Certainly within this research, the pressure of increased throughput, and associated with this a variety of measures to decrease the length of hospital stay, were found to have created problems for the nurses. Sbaih (2002) has also found that nurses in accident and emergency departments experienced tensions due to the temporal structure being imposed on them.

\section{Listening Time}

Listening to a patient's experience and understanding the meaning for that patient has been identified as a significant factor contributing to the quality of patient care (Tanner et al., 1993, Radwin, 1995). This creation of shared meaning is that illness as lived is distinct from the phenomenon of the disease itself 
(Toombs, 1992). The ability to listen to patients' experiences as told by them is essential to this process and one that Toombs (1992) argues that medical staff do not do. While this is a time-consuming process for nurses it can be deemed worthy of investing time.

I think that a person's nursing needs are often much deeper and that you have cannot actually battle the way out through difficult problems, without having some idea of the patient's concept of themselves. You have to be able to get to know them and their family, all factors that influence their life to be able to have a truly accurate picture in your own mind about what difference you can make. That counts. (SS13)

For this nurse, getting to know the patient accords the privileged knowing that is needed in order to define his situation as an effective practitioner. Needing time with the patient is for him about real nursing making a difference. However, knowing the patient in this way can place additional demands on nurses, not only from the investment in time needed to get to know the patient, but by the nature of what is revealed about the patient. This may require further action in extending the nurses' work and the additional time required for this. In their study of medical residents' time management, Yoels and Clair (1994) state how the humanistic approaches in medicine present challenges for doctors' time control. This may also account for the way in which some nurses actively manage their time by not getting to know too much about a patient. In this way, the nurses' control of time is also about controlling the interaction and degrees of knowing the patient.

\section{Wasting Time}

As a contrast to the temporal reference framework of needing time is that of wasting time. That time can be wasted is fundamental to the western time framework and the Protestant work ethic (Adam 1995). A charge nurse expressed his irritation about certain work that nurses were expected to do, in providing cover work that other health care workers could do, as in the following extract.

Dishing up food, although I understand the importance of patients being able to eat and that nurses should be allowed to help feed them and manage themselves. Trying to pick up the patients property from somewhere, or do this, do that, these aspects of our work are dreadful. They support the old fashioned idea that nurses are the housekeepers of the hospital. (SS.13)

That nurses' time can be wasted is not just about what the charge nurse referred to as specific tasks, but encompasses processes and patients and how these come to be incorporated into the temporal reference framework. Nurses themselves 
who are learning to manage their time are conscious of their 'taking up the time' of more experienced nurses. A student nurse expressed her appreciation of the staff nurse who was willing to spend time with her: 'Well it would be really easy for her to do it instead of having to watch me do it' (II:7). For this nurse her own temporal framework of needing time with an experienced nurse also serves as a source of tension as she recognizes that she can be a cause of time wasting for another. On this basis, nurses come to recognize that within this temporal reference framework they themselves can contribute to wasting time. This applies to patients who come to recognize that they can be a source of time wasting for health care workers (Roth, 1963). Nurses' class certain patients as 'time wasters', which is a factor in how some patients can become labelled as 'unpopular' (Stockwell, 1972), with the nurses perceiving these patients as demanding.

We have a patient she is a 'bell ringer', she is constantly buzzing for a nurse and it is unnecessary. You know she will buzz and say can you move my bedtable. It is such a waste of our time. (II.6)

As a site for misunderstanding, patients also have their temporal reference frameworks, and as stated previously they consist of expectations and consequences. In their own minds these patients may be making reasonable requests of the nurses' time. For this nurse, this patient represents not only a waste of time, but also an interruptive factor influencing her sense of time control. The nurse also has to control the emotions associated with what she perceives to be a waste of time, concealing her negative feelings, as it is inappropriate for her to vent these in front of patients. As part of nurses' emotional work, they require the ability to present many faces according to the circumstances required (Bolton, 2001).

It is not only patients who may be judged as making unreasonable demands on the nurses' time: nurses may receive referrals from other nurses or health care workers that they deem as inappropriate and a waste of their time. For instance, in a rehabilitation setting patients were judged initially by members of the health care team to determine their suitability to be admitted to the unit.

When you go and assess them and talk to the patient before they come and you must make that quite clear how we work. Otherwise, it is wasting time when they get here. (FG4:20)

In effect, the patient has to put on a performance (Goffman, 1959) to convince the health care team that he or she will work at the rehabilitation process and as such will not waste their time. For the member of the health care team who is assessing the patient, there is the team responsibility for ensuring that the patients who are selected will not waste the team's time. Conflict can arise between workers who have different temporal reference frameworks, defining a situation from one perspective as 'needing time' in contrast to others who may define that situation as a waste of time. 


\section{Interrupted Work}

Nurses take for granted that their work should be interrupted either by others or by themselves (Waterworth et al., 1999). This temporal reference framework provides for the expectation that time with patients should be and can be subject to interruption. There is also the team influence on this frame and with it expectations and consequences as the following indicates.

I could tell there was something the matter with the patient. He was just lying there looking quiet. I went over to him and started talking to him and asking him how he was today. He started to open up to me. Telling me how he thought his leukaemia had come back. I knew he was upset and wanted to talk and I would need some time with him. So I pulled the curtains around the bed. The other nurses in the room knew I would not want to be disturbed. They kept an eye on the other patients for me. (N1)

Within the team, certain 'sign vehicles' (Goffman, 1959) act as 'time protectors'. Because of this, team members will provide some cover so that a nurse has protected time to be with a patient. While this involves extra work for the other nurses in that they have to provide cover work, it is accepted. The nurses in the study who worked in a unit that specialized in caring for dying patients who needed terminal care related how the bereaved relatives would often return to see the nurses. Despite this interrupting their work, the nurses acknowledged as a team that this was an important part of nursing for them. When a bereaved relative arrived on the unit this was a primary sign to the team that one nurse would need to have protected time with the person.

All the staff pick up on that though don't they? If there were somebody out of S's team, you would automatically take over their job, because you knew that she was more involved with that family. We all recognise that don't we? (FG2:11)

Understanding how they view spending time with patients or a relative also provides understanding of the meaning of nursing for these nurses and represents what for them is real nursing. As such this represents a continuity of caring time (Milne and McWilliman, 1996) which continues beyond the death of a patient.

Some nurses have more opportunity for creating time protection, particularly nurses who can formally schedule their work such as those who work as specialist nurses. These nurses have more autonomy than nurses who are a member of a ward nursing team rostered to work certain shifts. However, specialist nurses have pagers allocated to them so that they can be contacted, creating the impression of ever-availability. The pagers can clearly be a source of interruption, and as such the nurses had adopted strategies by which to minimize this.

In examining the temporal reference frameworks, the notion of 'status time' illuminates how power and control are present, yet implicit. Within teams, differences can arise so that some members of the team based on their status have 
more opportunity for protected time. Interruption rates for practice nurses and general practitioners were compared in a study by Paxton et al. (1996). Higher rates of interruptions were found in the nursing group in comparison to the general practitioners. The impact of the interruptions on the nurses involved them being distracted and nurse-patient communication being disrupted, contributing to work stress. Changes in practice did occur following presentation of the findings and overall interruption rates were reduced, although for the nursing group they remained at a higher level than for the general practitioners. As such the temporal reference frameworks can be the site for power differences aligned to the different status of health care workers.

\section{Conclusion}

As Zerubavel (1979) notes, there are multiple temporal reference frameworks and each has its own cognitive purpose. With this comes the possibility of conflict and tension for the individual, between individuals and in groups. This conflict and tension may be overt or covert and will influence the strategies the nurses use in the performance of time management. There is far more complexity underpinning what Zerubavel $(1979,1981)$ referred to as the socio-temporal order: 'How the sociotemporal order is implemented and realized in practice, in particular through social and discursive interaction, remains largely unexplored' (Zucchermaglio and Talamo, 2000: 207).

As in this research, the identification of specific temporal reference frameworks in actual practice provides a perspective for determining some of the complexity of this social and discursive interaction, as well as how groups (in this case the nursing profession) view their time use; in how the social constructions of temporal reference come to form the background expectancies for the nurses' time control and temporal organization of work. They determine the knowledge of what is relevant that comes to be incorporated in the professionals' underpinning practical knowledge that then becomes taken for granted as the way things are. Finding the existence of individual, team and organizational temporal reference frameworks is important for understanding the complexity of nurses' time and in particular for challenging the notion of time management as an individual activity. When temporal reference frameworks clash, they can be a source of tension in the provision of caring and commitment by health care professionals.

\section{Note}

My thanks to the reviewers of the article for their helpful comments. 


\section{References}

Adam, B. (1995) Timewatch: The Social Analysis of Time. Cambridge: Polity Press.

Allen, D. (1997) 'The Nursing-Medical Boundary: A Negotiated Order?', Sociology of Health and Illness 19(4): 498-520.

Blumenthal, D. and Epstein, A.M. (1996) 'The Role of Physicians in the Future of Quality Management', New England Journal of Medicine 355(17): 1328-31.

Bolton, S.C. (2001) 'Changing Faces; Nurses as Emotional Jugglers', Sociology of Health and Illness 23(1): 85-100.

Clarke, M. (1978) 'Getting Through the Work', in R. Dingwall and J. McIntosh (eds) Reading in the Sociology of Nursing. Edinburgh: Churchill Livingstone.

Department of Health (1991) The Patient's Charter. London: DoH.

Department of Health (1993) The Challenges for Nursing and Midwifery in the 21st Century. The Heathrow Debate. London: DoH.

Department of Health (1997) The New NHS: Modern and Dependable. London: DoH.

Evers, H.A. (1981) 'Tender Loving Care? Patients and Nurses in Geriatric Wards', in L.A. Copp (ed.) Care of the Ageing, pp. 46-74. Edinburgh: Churchill Livingstone.

Fine, G. (1996) The Culture of Restaurant Work. Berkeley: University of California Press.

Gibson, D. (1994) 'Time for Clients; Temporal Aspects of Community Psychiatric Nursing', Journal of Advanced Nursing 20: 110-16.

Giddens, A. (1987) Social Theory and Modern Sociology. Stanford: Stanford University Press.

Gilligan, C., Ward, J.V. and Taylor, J.M. (eds) (1988) Mapping the Moral Domain, a Contribution of Women's Thinking to Psychological Theory and Education. Cambridge: Harvard University Press.

Goffman, E. (1959) The Presentation of Self in Everyday Life. Harmondsworth: Penguin.

Goffman, E. (1974) Frame Analysis. New York: Harper.

Henderson, V. (1980) 'Preserving the Essence of Nursing in a Technological Age', Journal of Advanced Nursing 5: 245-60.

Hochschild, A. (1979) 'Emotion Work', American Journal of Sociology 95(3): 551-75.

Hochschild, A. (1997) The Time Blind. New York: Metropolitan Books.

Howie, J. (1998) 'Comment: Do Minutes Count for Quality in the General Practice Consultation', Journal of Health Service Research Policy 3(4): 213-14.

Jones, A.R. (2001) 'Time to Think: Temporal Considerations in Nursing Practice and Research', Journal of Advanced Nursing 33(2): 150-8.

McNeese-Smith, D.K. (2001) 'Staff Nurse Views of their Productivity and Nonproductivity', Health Care Management Review 26(2): 7-19.

Melia, K. (1987) Learning and Working: The Occupational Socialisation of Nurses. London: Tavistock.

Milne, H.A. and McWilliman, C.L. (1996) 'Considering Nursing Resource as "Caring Time", , Journal of Advanced Nursing 23(4): 810-19.

Novek, J., Yossi, A. and Spiegel, J. (1990) 'Mechanisation, the Labour Process and Injury Risks in the Canadian Meat Packing Industry', International Journal of Health Services 29(2): 281-96.

Padgett, S.M. (1998) 'Dilemmas of Caring in a Corporate Context: A Critique of Nursing Case Management', Advances in Nursing Science 20(4): 1-12. 
Paxton, F., Howie, J. and Porter, M. (1996) 'A Study of Interruption Rates for Practice Nurses and GPs', Nursing Standard 10(43): 33-6.

Peters, P. (1999) 'Time Allocation in Times of Structural Transformation', Time \& Society 8(2): 329-56.

Radwin, L.E. (1995) 'Knowing the Patient: A Process Model of Individualised Interventions', Nursing Research 44(6): 364-70.

Reed, J. and Procter, S. (1995) Practitioner Research and Health Care, the Inside Story. London: Chapman \& Hall.

Roth, J. (1963) Timetables. Indianapolis: Bobbs Merrill.

Sbaih, L.C. (2002) 'Meanings of Intermediate: The Practical Use of the Patient's Charter in the Accident and Emergency Department', Social Science and Medicine 54: $1345-55$.

Schutz, A. (1964) 'The Well Informed Citizen. An Essay on the Social Distribution of Knowledge', in A. Broderson (ed.) Collected Papers II. The Hague: Nijoff.

Stockwell, F. (1972) The Unpopular Patient. London: Royal College of Nursing.

Tanner, C., Benner, P., Chesla, C. and Gordon, D.R. (1993) 'The Phenomenology of Knowing the Patient', Image, Journal of Nursing Scholarship 25(4): 273-80.

Toombs, S.K. (1992) The Meaning of Illness. A Phenomenological Account of the Different Perspectives of Physician and Patient. Dordrecht: Kluwer.

Walsh, K. (1997) 'Encounters, Endings and Temporality in Psychiatric Nursing', Journal of Advanced Nursing 25(3): 485-91.

Waterworth, S., May, C. and Luker, K.A. (1999) 'Clinical Effectiveness and Interrupted Work', Clinical Effectiveness in Nursing 3: 163-9.

Yoels, W.C. and Clair, J.M. (1994) 'Never Enough Time. How Medical Residents Manage a Scarce Resource', Journal of Contemporary Ethnography 23(2): 185-213.

Zerubavel, E. (1979) Patterns of Time in Hospital Life. Chicago: University of Chicago.

Zerubavel, E. (1981) Hidden Rhythms. Schedules and Calendars in Social Life. Chicago: University of Chicago.

Zucchermaglio, C. and Talamo, A. (2000) 'The Social Construction of Work Times. Negotiated and Expected Time', Time \& Society 9(2/3): 205-22.

SUSAN WATERWORTH is a senior lecturer at the School of Nursing, Faculty of Medical and Health Sciences, Auckland University, New Zealand. She has a special interest in temporality in health care, particularly from the perspective of health care workers, especially nurses. ADDRESS: The University of Auckland, Private Bag 92019, Auckland, New Zealand.

[email susanpw@xtra.co.nz] 